\title{
Creación de un comité de vía aérea quirúrgica para la decisión de traqueostomía electiva en pacientes críticos COVID-19
}

\section{Creation of a surgical airway committee for elective tracheostomy decision in critically ill patients COVID-19}

\author{
Martín Bolívar R. ${ }^{1}$, José Niebla M. ${ }^{1}$, Erika Celis A. ${ }^{2}$, Adrián Pamanes L. ${ }^{1}$, Marcel Cázarez A. ${ }^{1}$, \\ Benny Osuna $W^{1}{ }^{1}$, Héctor Echeagaray S. ${ }^{2}$, Ramón Montiel T. ${ }^{3}$
}

\section{Resumen}

La traqueostomía es un procedimiento ampliamente utilizado en pacientes críticos en la unidad de cuidados intensivos, con sus indicaciones, contraindicaciones, beneficios y complicaciones. El virus de SARS-CoV-2 afecta el tracto respiratorio y puede provocar complicaciones pulmonares graves que requieren, en ocasiones, intubación endotraqueal y ventilación mecánica prolongada como parte de su tratamiento. La infección por este virus tiene alto riesgo de contagio por medio de aerosoles con alta letalidad. Además, la traqueostomía es un procedimiento altamente productor de aerosoles, por lo que nos exige tomar las consideraciones para su indicación. Es imperioso tener las recomendaciones y/o guías para su realización. La formación de un comité especializado en la valoración quirúrgica de la vía aérea es necesario en todos los hospitales que atiendan pacientes con SARS-CoV-2.

Palabras clave: Traqueostomía, SARS-CoV-2, COVID-19, seguridad, comité.

\begin{abstract}
Tracheostomy is a procedure widely used in critically ill patients in the intensive care unit, with its indications, contraindications, benefits and complications. SARS$\mathrm{CoV}-2$ virus affects the respiratory tract and can cause severe pulmonary complications that could require endotracheal intubation and long-term assisted mechanical ventilation as part of its treatment. Infection caused by this virus has a high contagious risk through aerosols with high lethality. Furthermore, tracheostomy is a highly aerosol-producing procedure, this requires us to consider the indications of this procedure. It is imperative to have the recommendations and/or guidelines for its implementation. It is essential to develop a surgical airway evaluation specialized committee in every hospital that attends SARS-CoV-2 patients.
\end{abstract}

Keywords: Tracheostomy, SARS-CoV-2, COVID-19, safety, committee.

\author{
'Servicio de Cirugía General del \\ Centro de Investigación y Docencia en \\ Ciencias de la Salud de la Universidad \\ Autónoma de Sinaloa y el Hospital \\ Civil de Culiacán, Culiacán. Sinaloa, \\ México. \\ ${ }^{2}$ Servicio de Otorrinolaringología del \\ Centro de Investigación y Docencia en \\ Ciencias de la Salud de la Universidad \\ Autónoma de Sinaloa y el Hospital \\ Civil de Culiacán, Culiacán. Sinaloa, \\ México. \\ ${ }^{3}$ Servicio de Cirugía de Tórax del \\ Hospital General de Culiacán, \\ Culiacán. Sinaloa, México. \\ Los autores declaran no tener \\ conflictos de interés. \\ Recibido el 19 de octubre de 2020. \\ Aceptado el 17 de enero de 2021. \\ Correspondencia: \\ Martín Bolívar R. \\ Calle Eustaquio Buelna 91, \\ Colonia Gabriel Leyva, CP. 80030 \\ Culiacán. \\ Sinaloa, México. \\ Email: bolivarmartin64@hotmail.com
}

\section{Introducción}

La enfermedad COVID-19 es causada por el coronavirus de tipo 2 del síndrome respiratorio agudo severo (SARS-CoV-2, por sus siglas en inglés) nombrada oficialmente por la Organización Mundial de la Salud (OMS) el 11 de febrero de 2020, previamente llamada infección por el nuevo coronavirus de 2019 (2019-nCoV), al ser encontrado por primera vez en las vías respiratorias de pacientes con neumonía en Wuhan, en Hubei China, en diciembre de 2019. Es un virus RNA, con envoltura, no segmentado que tiene un diámetro de $65 \mathrm{~nm}$ a $125 \mathrm{~nm}$ y que presenta espigas en su superficie en forma de corona. Presenta cuatro estructuras principales de glicoproteína: espiga, envoltura, membrana y nucleocápside. La espiga es la porción externa del virus y forma homotrímeros que sobresalen en la superficie 
que facilitan su unión a las células huésped por atracción con la enzima convertidora de angiotensina 2 , que es la vía de entrada al tracto respiratorio inferior, ocasionando su replicación y desarrollo de la enfermedad ${ }^{1}$.

La pandemia actual por el virus SARS$\mathrm{CoV}-2$, responsable de la enfermedad COVID-19, tiene a la comunidad de la salud de todo el mundo en una lucha constante. Al día 19 de octubre de 2020, se han reportado en todo el mundo 338.096 casos nuevos, 39.944.882 casos confirmados y 1.111 .998 fallecidos. En las Américas 18.709.984 casos confirmados y 607.396 defunciones. En Chile 491.769 casos confirmados y 13.635 defunciones $^{2}$. En México al 18 de octubre se han reportaron 851.227 casos confirmados y 86.167 defunciones ${ }^{3}$.

La experiencia en China sugiere que entre el 9,8\% y el $15,2 \%$ de los pacientes hospitalizados requerirán ventilación mecánica invasiva u oxigenación por membrana extracorpórea, con una tasa de mortalidad en los pacientes con cuidados intensivos hasta del 50\% $\%^{4-6}$.

En la ciudad de Nueva York, en Estados Unidos, se estudiaron 5.700 pacientes hospitalizados, el 14,2\% fue tratado en la unidad de cuidados intensivos (UCI), 12,2\% requirieron ventilación mecánica invasiva, con una mortalidad del $88,1 \%{ }^{7}$. Un estudio realizado en Italia, de 1.591 pacientes infectados con SARS-CoV-2 admitidos en UCI reportó que 1.150 pacientes $(88 \%)$ requirieron intubación endotraqueal y ventilación mecánica ${ }^{8}$.

La traqueostomía en pacientes con intubación endotraqueal y ventilación mecánica es ampliamente utilizado en la UCI, sus indicaciones aunque no son absolutas son: prevención del daño laríngeo con estenosis subsecuente de la subglotis y de la vía aérea alta por intubación prolongada (7 días, sin posibilidad de destete de ventilación mecánica), facilitar el manejo de secreciones, reducción de espacio muerto, obstrucción de vía aérea, imposibilidad de intubación orotraqueal por vía aérea difícil y destete de la ventilación mecánica. Las contraindicaciones que tampoco son absolutas son: rechazo anticipado de la traqueostomía, situación al final de la vida, shock séptico no controlado y disfunción orgánica múltiple con alto riesgo de muerte; incluidas en este rubro debe de considerarse el retraso de la traqueostomía si el paciente tiene el requerimiento respiratorio muy elevado $\left(\mathrm{Fio}_{2}>70 \%\right.$ y/o PEEP $>12$ $\mathrm{cmH}_{2} \mathrm{O}$ ), necesidad de prono en las 48 horas previas, inestabilidad hemodinámica con necesidad de soporte vasoactivo, coagulopatía con alto riesgo hemorrágico $\mathrm{y}$, aunque más relativa, la imposibilidad de obtener consentimiento informado?

Ahora bien, para la traqueostomía en pacientes COVID-19 las contraindicaciones son las mismas, donde hay cambios a manera de recomendaciones es en las indicaciones tales como: Indicar traqueostomía en pacientes que requieren ventilación mecánica a partir de 14 días de que se realizó la intubación endotraqueal ( 2 a 3 semanas) con la condicionante que el paciente tenga estabilidad clínica y no presente contraindicaciones. Se deberá plantear traqueostomía precoz solo en caso de pacientes estables en quienes se sospecha que requerirán ventilación mecánica prolongada por otros motivos que no es COVID-19, se deben usar cánulas con balón no fenestradas y mantener el balón inflado con una presión de 25 a $30 \mathrm{~cm}$ $\mathrm{H}_{2} \mathrm{O}$ (18-22 $\mathrm{mmHg}$ ) para lograr un adecuado sellado sin riesgo de isquemia de la tráquea, utilizar sistema de aspiración cerrado, retrasar lo más que se pueda el recambio de la cánula endotraqueal, usar siempre el EPP adecuado y extremar precauciones al desinflar el balón de la sonda endotraqueal al iniciar el destete del ventilador'

Para realizar traqueostomías en los pacientes críticos COVID-19 que requieren de ventilación mecánica asistida, se tienen que analizar varios aspectos para la toma de decisiones. Primeramente, por su alta transmisibilidad, se debe conocer el riesgo de infección del personal de salud que intervendrá en el procedimiento. Otro aspecto es saber si al realizar la traqueostomía los pacientes presentan disminución en la morbimortalidad. No menos importante, es establecer si en los pacientes a quienes se les realiza la traqueostomía presentan disminución en el tiempo de sedación, o bien, la disminución de medicamentos requeridos, así como saber si existe reducción de la cantidad del personal de salud especializado para su atención requerido, posterior a la traqueostomía, logrando optimización de recursos, camas en UCI y reducción de costos. 
La toma de decisiones para la realización de la traqueostomía deberá ser mediante un comité multidisciplinario de vía área, en apego a indicaciones y contraindicaciones en cada paciente de acuerdo a tiempo de intubación, edad, falla orgánica, comorbilidades y pronóstico. Establecer el equipo de protección personal adecuado y seguro, protocolos preoperatorios, transoperatorios y posoperatorios a seguir, área en que se realizará, técnicas de traqueostomía más segura y seguimiento de los pacientes. El objetivo de la presente investigación es describir la creación de un comité multidisciplinario de vía aérea para mejorar la calidad de atención del paciente con COVID-19 y disminuir los riesgos al personal de salud. Debido a la necesidad de terapia intensiva y el personal multidisciplinario requerido, un hospital de segundo o tercer nivel de atención es el adecuado para la implementación del comité.

\section{El riesgo de infección del personal de salud que interviene en la traqueostomía}

El riesgo de realizar traqueostomías en pacientes infectados por SARS-CoV-2, el papel de la carga viral y el contar prequirúrgicamente con la RT-PCR, ya sea positivas o negativas aún se desconoce, sin embargo, con la evidencia generada en China del estudio de $\mathrm{Wu}$ y cols. con 72.314 casos, se demostró que el 3,8\% (1.716 casos) eran personal de salud expuesto y que el $14,8 \%$ de los infectados se clasificaron como severos ${ }^{4}$. Aún así, se sabe que la traqueostomía es un procedimiento generador de aerosoles y con la evidencia basada en las traqueostomías realizadas durante la epidemia de SARS, se demostró que la transmisión en el personal de salud tiene riesgo relativo de $4,15(1,50-11,50)$ con $95 \%$ de intervalo de confianza ${ }^{10}$.

\section{Rol de la traqueostomía en la morbimorta- lidad de pacientes COVID-19}

La evidencia en pacientes críticamente enfermos infectados por SARS-CoV-2 bajo ventilación mecánica y realizar traqueostomía temprana o tardía es desconocida. En dos metaanálisis realizados previos a COVID-19, en donde compararon la realización de traqueostomía temprana (< 10 días) y tardía ( $>10$ días), encontraron resultados favorables en la traqueostomía temprana en cuanto la dis- minución del tiempo de estancia en $\mathrm{UCI}^{11,12}$, uno de ellos reportó menor mortalidad en traqueostomía temprana ${ }^{11}$, mientras que el otro no encontró diferencia significativa en este rubro ${ }^{12}$. Bateman y cols. en su estudio encontraron que en pacientes críticamente enfermos no-COVID-19, no hubo diferencia en la supervivencia a largo plazo en pacientes con ventilación mecánica asistida con traqueostomía y sin traqueostomía después del fracaso del destete, sugiriendo que la supervivencia de estos pacientes depende más de las enfermedades subyacentes que de la ventilación en $s^{13}$.

En un estudio realizado en Lombardi, Italia, con más de 100 pacientes críticos infectados por SARS-CoV-2 con necesidad de ventilación mecánica, en los que se realizó traqueostomía electiva a 32 pacientes ( 10 percutáneas y 22 abiertas), en un periodo aproximado de 15 días (9 a 21) después de la intubación, no se registró mortalidad relacionada al procedimiento y la mortalidad de estos pacientes fue de $15,6 \%$, la cual ocurrió dentro de los primeros 7 días ${ }^{14}$. Es importante remarcar que los pacientes críticos por COVID-19 tienen una alta mortalidad, que varía mucho desde $16 \%$ hasta $78 \%$ de acuerdo a diferentes estudios ${ }^{15}$.

\section{La traqueostomía y sus beneficios en pacientes COVID-19}

Algunos de los beneficios que tiene realizar traqueostomía en pacientes críticamente enfermos son: disminución del tiempo con ventilación mecánica invasiva, disminución de la estancia en UCI, mejor comunicación del paciente, mejoría de la calidad de vida, reducción del daño y disfunción de las cuerdas vocales ${ }^{16}$; en pacientes críticos no COVID-19 el tiempo de requerimiento de ventilación mecánica invasiva y estancia en UCI, dependerá en gran medida a la patología que los llevó a esta situación. En pacientes críticos COVID-19 con intubación prolongada, otro beneficio de la traqueostomía es brindar un sistema sellado para asistencia respiratoria continua y esto puede ser preferible a la extubación primaria con un alto riesgo de falla, teniendo presente que el proceso de extubación es de alto riesgo de aerolización. También permite un menor requerimiento de sedación, menos bombas de infusión, minimizando el riesgo de 
complicaciones asociadas a sedación, facilita la atención y la posibilidad de que su atención sea supervisada por personal de enfermería capacitado en cuidados no intensivos ${ }^{17}$, todos estos beneficios son de ayuda en esta contingencia ya que uno de los objetivos principales es optimizar los recursos.

\section{Indicaciones y contraindicaciones de traqueostomía en paciente COVID-19}

Se debe considerar que en pacientes $\mathrm{CO}$ VID-19 las indicaciones y contraindicaciones para realizar traqueostomías no son absolutas. Las principales indicaciones para la traqueostomía en pacientes COVID-19 incluyen protección y acceso a la vía aérea para eliminar secreciones, ventilación mecánica asistida prolongada, obstrucción de la vía aérea superior y reducción del espacio muerto para facilitar el destete ventilatorio ${ }^{18}$. El desarrollo de nuevos instrumentos y la estandarización de las técnicas han reducido los riesgos de manera que prácticamente no hay contraindicaciones absolutas, salvo el trastorno de la coagulación severa no corregida (INR $\geq 2,0$; plaquetas $\leq 20.000$, protrombina $<55 \%$, y/o fibrinógeno $<100 \mathrm{mg} / \mathrm{dL})^{19}$. Las contraindicaciones relativas son: trastorno de la coagulación (INR $\geq 1,5$, plaquetas $\leq 50.000$ ), cuello corto (circunferencia del cuello $46 \mathrm{~cm}$, con una distancia entre el cartílago cricoides y la muesca esternal de $2,5 \mathrm{~cm}$ ), obesidad, bocio tiroideo, infección de los tejidos blandos en el cuello, incapacidad para extender el cuello, presencia de vasos pulsátiles en la región, malignidad local, antecedentes de cirugía cervical o traqueostomía, historia de radioterapia en la región cervical (en las últimas 4 semanas) y requerimiento de valores altos en el soporte ventilatorio $\left(\mathrm{FiO}_{2} \geq 70 \%\right.$, $\mathrm{PEEP}$ $\left.\geq 10 \mathrm{~cm} \mathrm{H}_{2} \mathrm{O}\right)^{18}$.

\section{Traqueostomía y el dilema de su tiempo de ejecución en pacientes COVID-19}

Uno de los factores importantes para considerar realizar traqueostomía en el paciente COVID-19 es el tiempo, ya que se debe de considerar la carga viral del paciente y riesgo de contagio al personal de salud. Adicionalmente se debe considerar el tiempo de enfermedad crítica y el pronóstico del paciente. Aún no se cuenta con evidencia que considere el mejor tiempo para realizar este procedimiento y mediante el riesgo de muerte podemos inferir que no se deben realizar traqueostomías tempranas, ya que, el tiempo medio de mortalidad desde su admisión hospitalaria, en Wuhan, demostró una media de 5 días², y en Lombardi, Italia fue de 7 días $^{8,20}$. Takhar y cols. mencionan el tiempo para la traqueostomía en pacientes COVID-19, en la que toma en cuenta la sintomatología, pronóstico, carga viral y seguridad del personal de salud a las 2 y 3 semanas, observando disminución del riesgo de aerolización y contaminación en promedio a los 20 días, por lo que recomienda traqueostomía no antes de los 14 días, ideal a los 21 días o más de la intubación ${ }^{17}$. Es de importancia la carga viral en el transcurso de la enfermedad para la decisión de realizar el procedimiento, estando presente desde el periodo de incubación después de la exposición al virus (periodo asintomático) correspondiendo a 5 días (4-14), haciéndose más abundante al iniciar los síntomas, disminuyendo 3 a 4 días después. Sin embargo, en pacientes con enfermedad grave y crítica, la carga viral es más abundante y disminuye más lentamente, dato de gran impacto ya que los pacientes que requerirán traqueostomía se engloban en esta situación, por lo que se señala una ventana de oportunidad realizarla 16 a 30 días desde el inicio de los síntomas ${ }^{21}$. Considerando lo anterior, 21 días es lo más pertinente, sin embargo, en pacientes excepcionalmente, bajo una selección adecuada, pudiese ser una alternativa a los 14 días.

\section{Creación de un comité especializado en la valoración del manejo quirúrgico de la vía aérea}

La toma de decisión para realizar o no una traqueostomía en pacientes COVID-19, debe de ser tomada multidisciplinariamente y se deben individualizar los $\operatorname{casos}^{17,22,23}$. Ante esta postura en nuestro centro, como la mejor opción, se tomó la decisión de que la realización de una traqueostomía en pacientes COVID-19, no debe de ser tomada por una sola persona, por lo que deberá ser sometida a consenso entre el personal de salud especialista en el área de su competencia para este fin, los cuales deberán ser integrados en un grupo de trabajo para la presentación, discusión y decisión de cada caso, por lo que la formación o creación 
de un comité, ante la alta transmisibilidad de SARS-CoV-2 y su letalidad es necesario. La creación del comité de vía aérea es algo optativo de cada centro hospitalario.

En este contexto es prioridad la protección del personal de salud que intervendrá en el procedimiento tomando en cuenta los beneficios de la traqueostomía que en pacientes críticos COVID-19 pueda tener, debido a la alta mortalidad que por sí misma esta enfermedad tiene en estos pacientes $(17 \%-78 \%)^{15}$. El comité especializado en la valoración del manejo quirúrgico de la vía aérea deberá estar conformado por 2 especialistas en medicina crítica a cargo del paciente, que proponen realizar el procedimiento, 2 cirujanos generales o cirujanos de tórax, 2 otorrinolaringólogos o cirujanos de cabeza y cuello y 2 anestesiólogos. Debido a que cada hospital puede estar dotado de un comité de ética clínico, estos podrán ser consultados cuando el caso lo amerite, ya sea por conflictos de opinión, urgencia o retraso en el procedimiento. El comité deberá de sesionar en forma programada, con participación de un mínimo de 6 de sus integrantes (75\%) y siempre con la presencia de las 4 especialidades, idealmente por vía virtual o en su caso en área con las medidas de sana distancia y protección personal adecuada, para discutir el o los casos propuestos.

La decisión final sobre cada caso será idealmente por unanimidad o bien por mayoría, en caso de una decisión dividida igualitaria, se reprogramará para otra sesión, después de mejorar las condiciones de salud del paciente que resultaron en la decisión dividida. En caso de la toma de decisión a favor de realizar el procedimiento, se llevarán a cabo los preparativos preoperatorios y se programará la traqueostomía con la técnica quirúrgica, percutánea o abierta, así como el sitio para su realización. En caso de decidir no realizar la traqueostomía, se deberá de revalorar el caso posterior a corregir o mejorar las condiciones que hayan sido objeto de rechazo y deberá ser propuesto nuevamente por 2 especialistas en medicina crítica a cargo del paciente. Se muestran el algoritmo en la Figura 1. Todas las decisiones del comité se deberán plasmar en el expediente clínico del paciente y dejar constancia en un acta de sesión del comité, firmada por todos los integrantes que intervinieron.

\section{Toma de decisiones para realizar la traqueostomía electiva mediante un comité multidisciplinario de vía aérea}

Consideramos como mejor opción los criterios de selección de pacientes COVID-19 para la realización de traqueostomía, modificados de Takhar y cols. los siguientes:

- Los pacientes pueden ser considerados para traqueostomía a partir del día 21 de la intubación y exista requerimiento continuo de ventilación mecánica asistida.

- En caso de pacientes con condiciones adecuadas, que cumplan los requerimientos para la traqueostomía y esta sea absolutamente necesaria para la mejoría clínica y sobrevida del paciente, puede ser considerado para la traqueostomía a partir del día 14 de la intubación y exista requerimiento de ventilación mecánica asistida.

- Cada caso debe ser revisado y propuesto por al menos dos especialistas experimentados en medicina crítica a cargo del paciente (intensivista, medicina interna o neumólogo)

- La técnica y lugar de su realización deben ser acordadas entre el equipo de medicina crítica a cargo del paciente y equipo quirúrgico.

- Requerimientos de ventilación apropiados $\left(\mathrm{FiO}_{2} \leq 50 \%\right.$, PEEP $\left.\leq 10\right)$.

- En pacientes donde el pronóstico no es claro, pacientes mayores ( $>70$ años) y/o falla orgánica múltiple, la traqueostomía debe diferirse.

- Cuando existan contraindicaciones para la traqueostomía (p. Ej. coagulopatía grave), la decisión del procedimiento se debe retrasar más allá de los 21 días.

- Se determinará el estatus más reciente de test diagnóstico de COVID-19 de ser posible y estar disponible ${ }^{17}$.

\section{Equipo de protección personal adecuado} (EPP) y seguro para realizar la traqueostomía y áreas indicadas para su realización

La decisión del uso de EPP adecuado y el lugar de realización para la traqueostomía, se tomó de importantes revisiones de la literatura, guías y recomendaciones realizadas por las más importantes asociaciones, colegios y revistas, recomendando que el EPP adecuado debe de constar de respirador purificador de 
Traqueostomía electiva en pacientes COVID-19, mediante un comité de vía aérea quirúrgica COVID-19

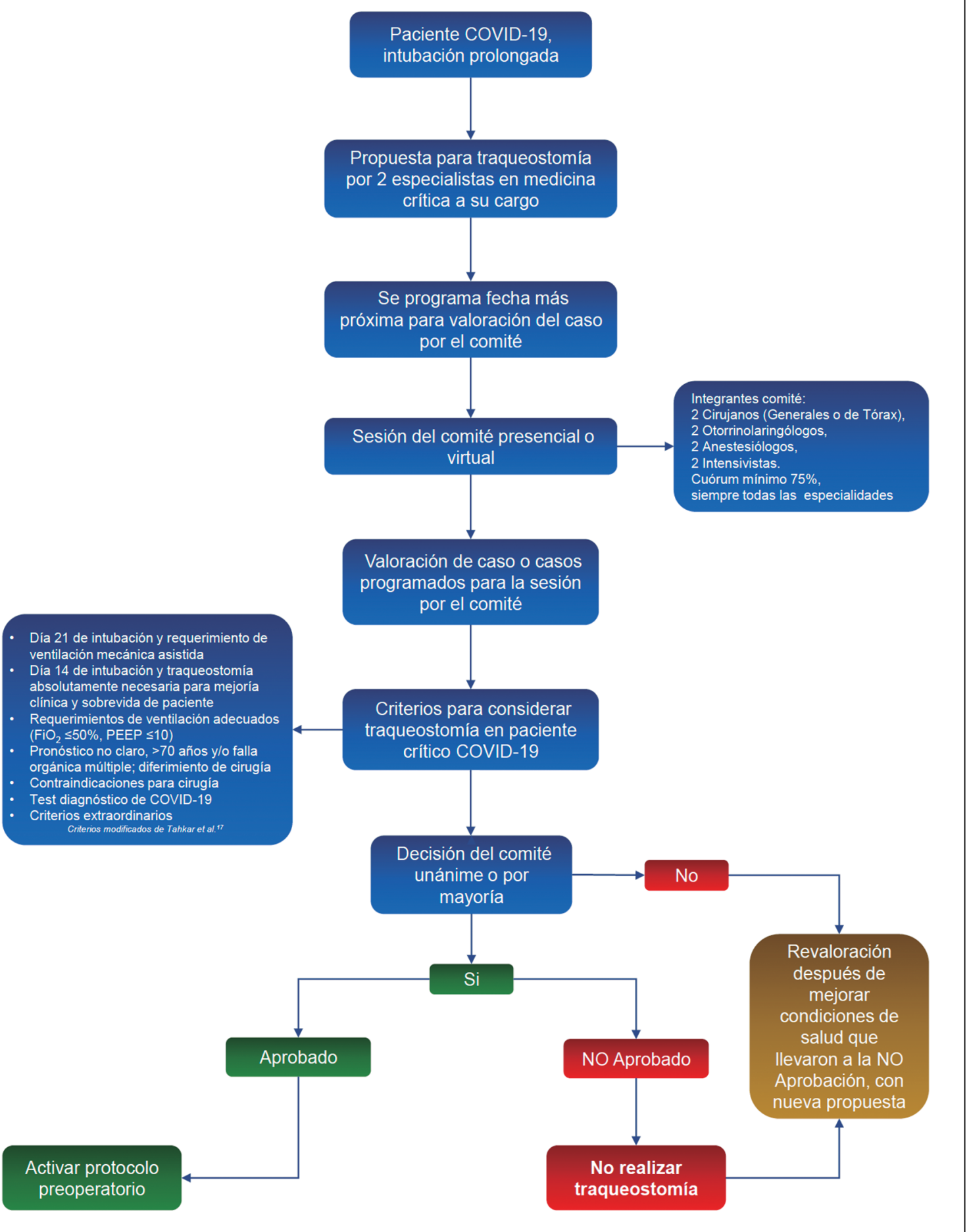

Figura 1. Algoritmo de toma de decisiones del comité de vía aérea quirúrgica COVID-19. 
aire motorizado (PAPR), N99, FFP3 o como mínimo N95, con o sin válvula de escape (opcional), bata larga impermeable, delantal impermeable, protección ocular, guantes, cubre botas y gorro. Como el área más segura para realizar el procedimiento recomiendan la sala de operaciones de presión negativa ${ }^{17,21-27}$, sin embargo, en muchos países, incluido México, es complicado contar con este sistema, por lo que se debe de optar por área específicas adecuadas para este fin tanto en UCI como en quirófanos, con las máximas medidas de seguridad y protección. Se ha mencionado un acrónimo muy útil llamado CORONA, el cual "C" representa cubrirse con las medidas de protección del personal ya mencionadas anteriormente, "OR" de "operating room", pabellón quirúrgico, el cual debe ser dedicado a pacientes con COVID-19, contar con todo el instrumental y requerimientos listos y a la mano; si la cirugía es en pabellón este deberá ser cerrado y no permitir el paso por al menos 3 horas. "O" de "open", de abrir la tráquea, tema que se mencionará más adelante y "NA" de "nurse and airway management" la cual requiere un entrenamiento especial de la vía aérea por parte de enfermería ${ }^{27}$.

\section{Técnicas seguras para la realización de traqueostomía}

Hablando de la seguridad del paciente con la evidencia en pacientes no-COVID-19, la técnica más segura para el paciente es la traqueostomía percutánea asistida por broncoscopía, ya que comparada con la abierta, tiene menor tasa de complicaciones ${ }^{16}$. En otros estudios se compara traqueostomía percutánea guiada por ultrasonido versus guiada por broncoscopía en pacientes críticos con ventilación mecánica asistida, sin encontrar diferencias en sus resultados ${ }^{13}$. La guía actual basada en evidencias para el uso de traqueostomía en pacientes críticos, no encontró diferencias en las técnicas percutáneas versus abiertas en cuanto la reducción de complicaciones en la técnica utilizada, neumotórax, sangrado y mortalidad. Sin embargo, recomienda la percutánea al encontrar menor riesgo de infecciones del estoma y menor costo al realizarse en la cama del paciente y no utilizar quirófano ${ }^{18}$. Takhar y cols. sugieren como una alternativa la técnica percutánea guiada por ultrasonido para disminuir la generación de aerosoles ${ }^{17}$. Sin embargo, otros autores consideran realizar la traqueostomía abierta con técnica de Björk para evitar formación de falsas vías y decanulación accidental ${ }^{22}$. Es de importancia hacer hincapié que el tipo de técnica de traqueostomía utilizada depende en gran medida de la disponibilidad de material y equipo en los hospitales, así como el entrenamiento y/o experticia del personal de salud para realizarla, por lo que debe ser acorde a estos elementos la selección de la técnica a utilizar.

\section{Integrantes del equipo para realizar tra- queostomía}

En nuestra institución se decidió, al determinar la mejor opción, que la selección de los integrantes del equipo y los términos para realizar traqueostomía en pacientes COVID-19 deben ser realizadas por equipos dedicados para llevar a cabo estos procedimientos con las habilidades y experiencia específicas necesarias para realizarlos de la manera más segura y oportuna posible, estos equipos no trabajarán más de 1 día por semana en este papel y no realizarán más de dos traqueostomías por día, y estarán trabajando dos días no consecutivos por semana. Esto se determinó después de una reunión de expertos en el tema en nuestro hospital, realizando por tanto una recomendación técnica en base a nuestra experiencia. Además, deberán llevar a cabo una previa capacitación bajo simulación, debiendo estar conformado cada equipo por 2 anestesiólogos expertos en manejo de vía aérea y broncoscopía, hay estudios que mencionan la asistencia de solo 1 anestesiólogo ${ }^{27}$ con el fin de minimizar el riesgo al personal, 2 cirujanos con experiencia en cirugía de cabeza y cuello y enfermería de cuidados intensivos ${ }^{17}$, sin embargo, se debe de adecuar al entorno hospitalario ya que en ocasiones es difícil contar con el personal especificado y se debe individualizar los recursos humanos con lo que se cuenta, siempre tomando en cuenta que sea el personal de salud con más experiencia.

Es de gran importancia, tanto la adecuada selección de los integrantes del equipo como lo es contar con protocolos de acción, que permitan llevar a cabo con éxito la traqueostomía y sobre todo con seguridad para el personal de salud que interviene. Además, sería una 
negligencia no tener todo preparado previo al procedimiento, con el conocimiento de que es generador de aerosoles y el alto riesgo de infección por SARS-CoV-2, por lo que se recomienda realizar una serie de pasos para planear con tiempo la traqueostomía programada ${ }^{28}$, realizando siempre los protocolos preoperatorio, transoperatorio y posoperatorio (Figura 2).

\section{Beneficios en la creación de un comité de vía aérea}

La creación de un comité de vía aérea, incentiva el trabajo en equipo, disminuye los errores y fortalece la seguridad de todo el personal. Debido a los grandes índices de infección prevalentes en el personal de la salud, el comité debe actuar como un supervisor de la seguridad del personal, así como un organismo intrahospitalario que decida los pacientes ideales para traqueostomía y los procedimientos a realizar, así como en el tiempo indicado para realizarla.

Tanto anestesiólogos, cirujanos, intensivistas deben de estar de acuerdo con las medidas a realizar en quirófano, así como buscar optimizar recursos y disminuir el riesgo de infección, salvaguardando la integridad y salud del paciente. El comité evita que una sola persona realice la decisión y, además, favorece que las medidas de seguridad se implementen en su totalidad. En un hospital escuela o con residencias médicas esto es más importante ya que minimiza la exposición de los estudiantes o los regula, como se comenta anteriormente el personal que entre a la sala de quirófano debe ser experimentado.

Una de las grandes controversias de esta enfermedad concierne a los pacientes que requieren traqueostomía con COVID-19 y el tiempo de ejecución de la misma, hasta el momento no hay evidencia clara de lo mejor para el paciente y el personal de salud, mien-

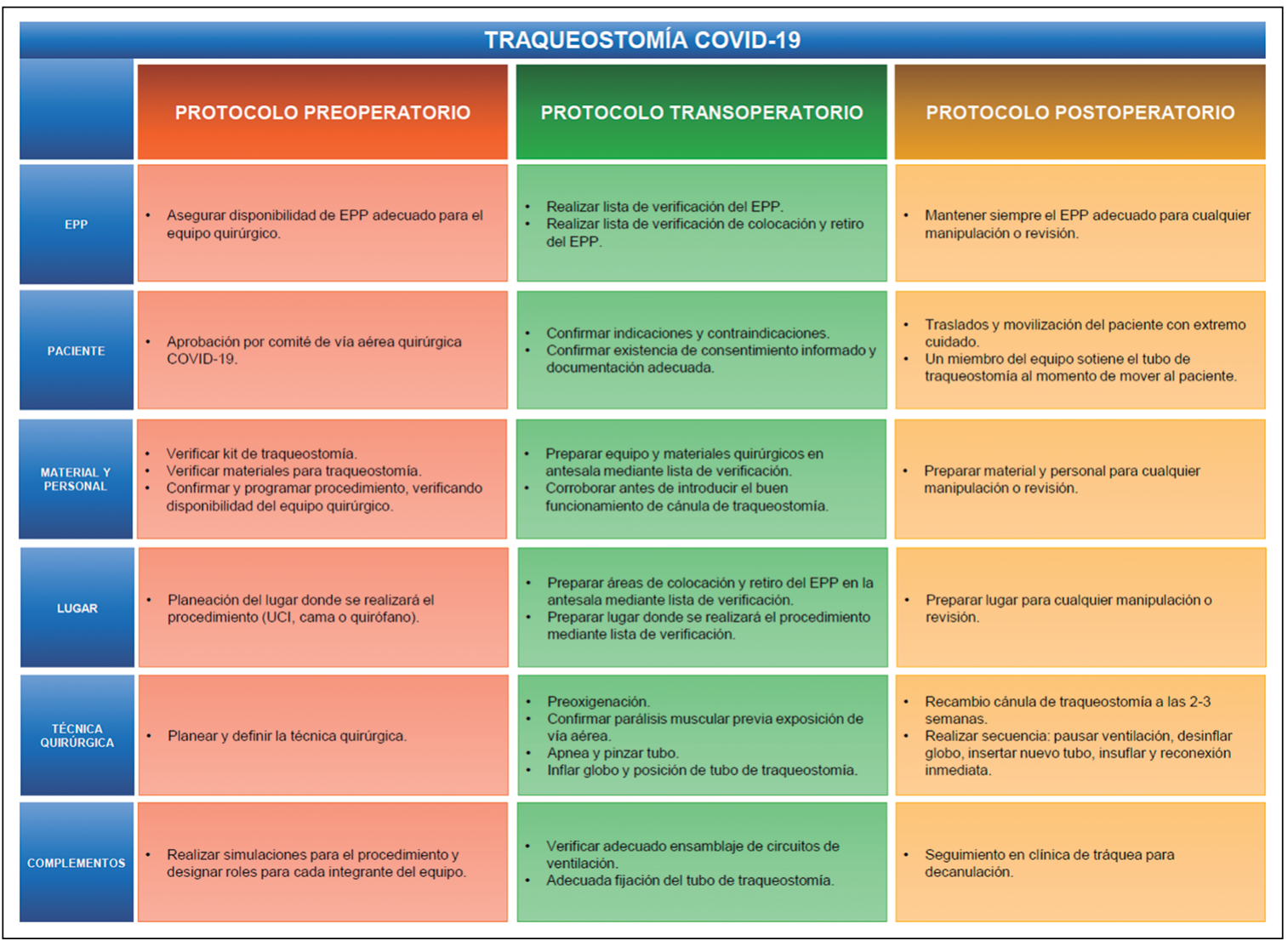

Figura 2. Protocolos preoperatorio, transoperatorio y posoperatorio de pacientes COVID-19 para realizar traqueostomía. 
tras en un estudio comentan que debe ser en 14 días $^{9}$ en otro, el más actual, que incluye 13 guías de traqueotomía y COVID-19, refiere que la mayoría de los centros eligen después de los 21 días el realizar la traqueostomía ${ }^{29}$. Es importante que ambas posiciones tienen ventajas y desventajas mientras la traqueostomía temprana a los 10 a 14 días, podría ayudar a extubar al paciente más rápidamente, así como disponer de más ventiladores, la traqueostomía a los 21 días podría seleccionar adecuadamente al paciente y disminuir el riesgo de contagio al personal de la salud. Es posible que con estudios posteriores y un conocimiento mayor que nos de la pandemia, podamos resolver esta controversia en el futuro.

\section{Conclusión}

El seguir los lineamientos internacionales para la realización de traqueostomía en pacientes críticos COVID-19, tanto su indicación, tiempo, personal que participa y medidas especiales de protección, incrementará el éxito de la cirugía, minimizando el riesgo al personal de la salud. Los comités son indispensables para lograr estas metas, por lo que se recomienda su creación en cada hospital que enfrente la actual pandemia de SARS-CoV-2.

\section{Bibliografía}

1. Astuti I, Ysrafil. Severe Acute Respiratory Syndrome Coronavirus 2 (SARS-CoV-2): An overview of viral structure and host response. Diabetes Metab Syndr. 2020;14(4):407-412.

2. World Health Organization. WHO Coronavirus Disease (COVID-19) Dashboard. Ginebra: World Health Organization; 2020 [Citado el 19 de octubre de 2020]. Disponible en: https://covid19.who.int

3. Gobierno de México. Covid-19 México. Información General. 2020 [Citado el 19 de octubre de 2020]. Disponible en: https://datos.covid-19.conacyt. $\mathrm{mx} / \#$ DOView

4. Wu Z, McGoogan J. Characteristics of and Important Lessons From the Coronavirus Disease 2019 (COVID-19) Outbreak in China. JAMA. 2020; 323(13):1239-1242.

5. Huang C, Wang Y, Li X, et al. Clinical features of patients infected with 2019 novel coronavirus in Wuhan, China. The Lancet. 2020; 395(10223):497506.
6. Wang D, Hu B, Hu C, et al. Clinical Characteristics of 138 Hospitalized Patients With 2019 Novel Coronavirus-Infected Pneumonia in Wuhan, China. JAMA. 2020; 323(11):1061-1069.

7. Richardson S, Hirsch J, Narasimhan M, et al. Presenting Characteristics, Comorbidities, and Outcomes Among 5700 Patients Hospitalized With COVID-19 in the New York City Area. JAMA. 2020;323(20):2052-2059.

8. Grasselli G, Zangrillo A, Zanella A, et al. Baseline Characteristics and Outcomes of 1591 Patients Infected With SARS-CoV-2 Admitted to ICUs of the Lombardy Region, Italy. JAMA. 2020;323(16):15741581.

9. Villalonga Vadell R, Martín Delgado MC, AvilésJurado FX, et al. Consensus Document of the Spanish Society of Intensive and Critical Care Medicine and Coronary Units (SEMICYUC), the Spanish Society of Otorhinolaryngology and Head and Neck Surgery (SEORL-CCC) and the Spanish Society of Anesthesiology and Resuscitation (SEDAR) on Tracheotomy in Patients with COVID-19 Infection. Documento de consenso de la Sociedad Española de Medicina Intensiva, Crítica, y Unidades Coronarias (SEMICYUC), la Sociedad Española de Otorrinolaringología y Cirugía de Cabeza y Cuello (SEORL-CCC) y la Sociedad Española de Anestesiología y Reanimación (SEDAR) sobre la traqueotomía en pacientes con COVID-19. Rev Esp Anestesiol Reanim. 2020;67(9):504-510. doi: 10.1016/j. redar.2020.05.001

10. Chen W, Ling W, Lu C, et al. Which preventive measures might protect health care workers from SARS? BMC Public Health. 2009;9:81.

11. Andriolo B, Andriolo R, Saconato H, Atallah Á, Valente O. Early versus late tracheostomy for critically ill patients. Cochrane Database Syst Rev. 2015;1(1):CD007271.

12. Liu C, Livingstone D, Dixon E, Dort J. Early versus Late Tracheostomy: A Systematic Review and Meta-Analysis. Otolaryngol. Head Neck Surg. 2015;152(2):219-227.

13. Bateman R, Sharpe M, Jagger J, et al. 36th International Symposium on Intensive Care and Emergency Medicine. Crit Care. 2016;20(S2):94.

14. Turri-Zanoni M, Battaglia P, Czaczkes C, Pelosi P, Castelnuovo P, Cabrini L. Elective Tracheostomy During Mechanical Ventilation in Patients Affected by COVID-19: Preliminary Case Series From Lombardy, Italy. Otolaryngol Head Neck Surg. 2020;163(1):135-137. doi: 10.1177/0194599820928963

15. Halacli B, Kaya A, Topeli A. Critically-ill COVID-19 patient. Turk J Med Sci. 2020;50(Sl-1):585-591.

16. Kidane B, Pierre A. From Open to Bedside Percutaneous Tracheostomy. Thorac Surg Clin. 2018;28(3):263-276.

17. Takhar A, Walker A, Tricklebank S, et al. 
Recommendation of a practical guideline for safe tracheostomy during the COVID-19 pandemic. Eur Arch Otorhinolaryngol. 2020;1-12.

18. Raimondi N, Vial MR, Calleja J, et al. Evidence-based guidelines for the use of tracheostomy in critically ill patients. J Crit Care. 2017;38:304-318.

19. Recomendaciones de la Sociedad Chilena de Medicina Intensiva para la consideración de una traqueostomía percutánea temprana en COVID-19. Sociedad Chilena de Medicina Intensiva (SOCHIMI). 2020 [Internet]. Citada el 31 de mayo de 2020. Disponible en: https://www.medicina-intensiva.cl/ site/covid/guias/TP_Temprana_SOCHIMI_2020.pdf

20. Leung C. Clinical features of deaths in the novel coronavirus epidemic in China. Rev Med Virol. 2020;30(3):e2103.

21. McGrath BA, Brenner MJ, Warrillow SJ, et al. Tracheostomy in the COVID-19 era: global and multidisciplinary guidance. Lancet Respir Med. 2020;8(7):717-725. doi: 10.1016/S22132600(20)30230-7

22. Chao TN, Braslow BM, Martin ND, et al. Tracheotomy in Ventilated Patients With COVID-19. Ann Surg. 2020;272(1):e30-e32. doi: 10.1097/ SLA.0000000000003956

23. Schultz P, Morvan J, Fakhry N, et al. French consensus regarding precautions during tracheostomy and post-tracheostomy care in the context of
COVID-19 pandemic. Eur Ann Otorhinolaryngol Head Neck Dis 2020;137(3):167-169.

24. Forrester J, Nassar A, Maggio P, Hawn M. Precautions for Operating Room Team Members During the COVID-19 Pandemic. J Am Coll Surg 2020;230(6):1098-101.

25. Sommer D, Engels P, Weitzel E, et al. Recommendations from the CSO-HNS taskforce on performance of tracheotomy during the COVID-19 pandemic. J Otolaryngol Head Neck Surg. 2020;49(1):23.

26. Jessop ZM, Dobbs TD, Ali SR, et al. Personal protective equipment for surgeons during COVID-19 pandemic: systematic review of availability, usage and rationing. Br J Surg. 2020;107(10):1262-1280. doi: 10.1002/bjs. 11750

27. Rappoport D, González T, Capdeville F, et al. Traqueostomía en pacientes con COVID-19: Recomendaciones actuales. Rev Cir 2020;72(5):577582.

28. Jacob T, Walker A, Mantelakis A, Gibbins N, Keane O. A framework for open tracheostomy in COVID-19 patients. Clin Otolaryngol. 2020;45(4):649-651. doi: 10.1111/coa.13549.

29. Heyd CP, Desiato VM, Nguyen SA, et al. Tracheostomy protocols during COVID-19 pandemic. Head Neck. 2020;42(6):1297-1302. doi: 10.1002/hed.26192. 